\title{
Empowering Healthcare Volunteer's through Participatory Action Research in a Comprehensive Healthcare Center
}

\section{Fatemeh Vizeshfar}

Shiraz University of Medical Sciences

Marzieh Momennasab ( $\nabla$ momennasab@sums.ac.ir)

Shiraz University of Medical Sciences

Shahrzad Yektatalab

Shiraz University of Medical Sciences

Mohamad Taghi Iman

Shiraz University

Research article

Keywords: Empowerment, Health, volunteers, Participatory action research

Posted Date: July 23rd, 2020

DOI: https://doi.org/10.21203/rs.3.rs-39458/v1

License: (ㅇ) (1) This work is licensed under a Creative Commons Attribution 4.0 International License. Read Full License 


\section{Abstract}

Background: healthcare volunteers act as the link between the society and the healthcare system and are a symbol of people's participation in the health maintenance and promotion. Despite the important role of health volunteers in the health system, it seems they experience several problems. The aim of this study was empowering health volunteers by determining and relining their problems through a participatory approach.

Methods: This study a participatory action research was done through two continuous cycles of reflection and acting for change over 20 months, in A comprehensive health center in Southern of Fars province in Iran.25 health volunteers, two instructors, and academic researcher as facilitator participate in this study. In the first cycle, the participants discovered the challenges of health volunteers prioritized them and an action plan was designed. Immersion and implementation of the plans were done. At the end of this cycle evaluation was done with the participants' cooperation. The second cycle began with reflecting on the results of the first cycle and final evaluation was done.

Results: Qualitative content analysis in the first phase led to the emergence of four major categories, including inefficiency of volunteers training, inefficiency of attraction and maintenance of volunteers, and being unknown to people and the major theme was named "unfertilized capacity". After the implementation of the operational

plan, the participants learned through reflection and immersing in action. Finally, quantitative content and data analysis showed improvement of knowledge and performance, satisfaction, effectiveness of programs and improvement in volunteer's competence.

Conclusions: Clarification of volunteers' roles, supporting volunteers to improve their knowledge and skills with coherent planning based on their educational needs, are appropriate management plans to attract and retain volunteers. By presenting their services to the society, they will be empowered and motivated to continue.

\section{Background}

Healthcare volunteers are people who spend their time and energy to serve other people and the society without receiving any money or financial reward $(12,24)$. Many volunteers serve in healthcare settings $(11)$. Many countries use volunteers for implementing governmental programs to enhance public health $(10,11,24,25)$. Volunteers play an important role in improving people's experience of care, create strong connections between the society and the services, facilitate care integrity, enhance public health, and reduce, health inequality (31). Many studies have been done on the positive effect of healthcare volunteers and most of them show that volunteers try to have an influential role in facilitating people's access to personal, familial, and social health goals. Since volunteers are role models in the society, they can have long term effects on people's understanding, beliefs, and attitudes (148). We aimed to identify the problems of healthcare volunteers and empower them through this participatory action research. Action research is one of the methods of creating change which is used to facilitate and enhance service providing in the industry, education, and newly the healthcare systems. Action research is a research method that emphasizes on participation, participants, and empowerment in groups experiencing inequality. Other features of this method include being practical, transformational, and cyclic (through reflection), emphasis on the process and how it affects the lives of the participants and that changing or making decisions are ultimately based on the benefactors. Thus, this method is suitable for research and change $(50,51)$. 


\section{Healthcare Volunteers in Iran}

In Iran, healthcare volunteers are women selected and invited from their residential area who are literate and socially accepted, and have time, motivation, and interest for social activities. Each volunteer should cover about 50 families in their neighborhood. To gain necessary health-related skills and awareness, the volunteers participate in weekly meetings in their local health centers. The educational content was about child, maternal, familial, and social health and common diseases. Besides learning scientific content and practical skills, the volunteers exercised what they learned in front of their trainer so they could better transfer the content to the families. Training consisted of primary and complementary courses. The primary course had a key role in strengthening the relations between the healthcare system and the volunteers. It was the foundation for later activities and attracting volunteers. One of the most important parts of the primary courses was identifying and prioritizing the neighborhood's health issues. These problems are identified and discussed during the meetings and a list of priorities is prepared. The complementary course starts after the volunteers begin their work and consists of various sessions and classes at the healthcare center. The course does not have any time limit. The volunteers and trainer agree upon the duration of the course and the time taken for each subject depends on the needs and conditions of the neighborhood. These sessions continue during the time the volunteers continue their work and they are provided with up-to-date knowledge about health-related issues. The subjects discussed are not limited and a wide range of issues are mentioned based on the volunteers' needs and requests $(20,36,37)$.

\section{Methods}

\section{Design}

This participatory action research was done in two cycles during 22 months from September 2016 to June 2018.

\section{Setting}

This study was done in a comprehensive healthcare center in Shiraz, the capital of Fars province, southwest Iran. In this comprehensive healthcare system, all healthcare services at primary and secondary prevention levels are done. These services include child health, reproductive health and pregnancy care, men and women's health, adolescent health, elderly health, vaccination, neonatal screening, breastfeeding promotion, marriage counseling and thalassemia screening, mental health, nutrition counseling, environmental health and occupational health. A family physician and a dentist also provide services to the population under coverage. The laboratory of this center performs occupational and marital tests as well as other routine medical tests. In the primary healthcare sector two public health and midwifery experts present health services to different age groups based on service packages. In the vaccination and neonatal screening section, two health and midwifery experts provide services to all related age groups. Other sections each have an expert with the related educational degree. The person who trains the volunteers not only teaches the volunteers, but is also responsible for school health and following and training family caregivers to the population under coverage. Nursing and midwifery students from different universities are present at these centers to be trained and undergo internships related to healthcare. Healthcare volunteers have an educational session every week on Sundays. Besides these routine sessions at the center, based on the volunteers' needs, smaller groups refer on 
other days to cooperate with the trainer and participate in screening programs, school training, family physician follow-ups, and other assigned duties.

\section{Participants}

The participants of this study were 25 healthcare volunteers and their instructors. Their previous instructor and the center's medical doctor also participated.

After obtaining necessary permissions, the volunteers and their instructor became familiar with the aims of the study and their questions were answered and they completed the informed consent forms.

\section{Research Tools}

Since action research emphasizes on triangulation and data collection $(52,74,75,109)$, we used different qualitative and quantitative methods such as interview, observation, focused group, record evaluation, Kirkpatrick model, volunteer performance monitoring form and survey.

\section{Data Collection}

\section{First cycle}

First stage: In the first stage of the first cycle, we determined the current status of healthcare workers over five months using different qualitative and quantitative methods: recording and transcribing eight focused group sessions, 25 hours of observation and self-reporting, eight in-depth interviews with the volunteers, two interviews with the instructors, assessing 30 volunteer performance monitoring checklists, analyzing 300 public survey forms and 30 volunteer survey forms, and assessing five documents. Obtained data were qualitatively and quantitatively assessed leading to a good understanding of the volunteers' current status and their challenges and competencies.

Second stage: In this stage, necessary plans for change were made which took three months. In this stage the aims, priorities, and plans were determined and designed.

Third stage: Immersion in action took three months. Healthcare volunteers played their role with new knowledge and skill. The researcher and instructor encouraged and supported them. All volunteers cooperated with people and their instructor based on the announced plan to implement screening plans for students and teaching the general public about health-related issues. Similar to other stages, the participants were encouraged to reflect on what they were doing during implementing the program.

Fourth stage: In the final stage, the plan was evaluated using qualitative and quantitative methods such as content analysis and volunteer survey over one month.

\section{Second Cycle}

This cycle took six months based on the results of the first cycle and its feedback. It consisted of reflection, action plan, immersion in action, and evaluation. 
Reflection: This stage took one month and comprised four group reflection sessions. The initial evaluation results were shared with the volunteers in the final stage of the first cycle. Gibbs model was used for reflection. As an educational method, reflection combined or connects action and thought $(115,117)$.

Action plan: During one month, new goals for change were designed. Most of the aims included empowering the volunteers scientifically to facilitate their independence in learning based on the health system's goals for this group.

Immersion in action: During three months, the volunteers were immersed in action in which 12 sessions were held for them in the presence of their instructor and the researcher as well as higher level authorities and those referring to the healthcare center. New plans were set or previous plans were completed and modified in order to reduced or solve the volunteers' problems and empower them.

Evaluation: Ultimately, final evaluation was done. During this stage, the measures taken to empower the volunteers were assessed qualitatively and quantitatively. In the qualitative approach, six in-depth interviews and two focused group sessions were held for the volunteers. Their activities were observed twice and field notes were taken. Moreover, eight volunteers wrote notes about their daily activities and the documents related to their performance were assessed. In the quantitative approach, 300 survey forms were completed by the general public and the volunteers' records were analyzed. The volunteer performance monitoring checklist was completed. Moreover, using Kirkpatrick's model, the educational program of the volunteers was evaluated with respect to their satisfaction with the program, knowledge gain, performance improvement, and effectiveness of the program from their point of view.

\section{Data analysis}

Quantitative data were analyzed using SPSS software, version 22. Conventional content analysis was used to assess qualitative data.

\section{Results}

In this study, besides method triangulation, data triangulation was also used. Table 1 shows the demographic characteristics of the participants.

Table 1: The demographic characteristics of the healthcare volunteers $(n=13)$ 


\begin{tabular}{|c|c|c|c|c|c|c|c|c|}
\hline $\begin{array}{l}\text { Volunteer } \\
\text { number }\end{array}$ & Role & Age & $\begin{array}{l}\text { Education } \\
\text { level }\end{array}$ & Job & $\begin{array}{l}\text { Marital } \\
\text { status }\end{array}$ & $\begin{array}{l}\text { Husband's } \\
\text { job }\end{array}$ & $\begin{array}{l}\text { Number } \\
\text { of } \\
\text { children }\end{array}$ & $\begin{array}{l}\text { Years of } \\
\text { volunteer } \\
\text { work }\end{array}$ \\
\hline 1 & Volunteer & 50 & $\begin{array}{l}\text { Middle } \\
\text { school }\end{array}$ & Housewife & Married & Freelance & 2 & 15 \\
\hline 2 & Volunteer & 47 & Diploma & Housewife & Married & retired & 4 & 5 \\
\hline 3 & Volunteer & 63 & $\begin{array}{l}\text { Primary } \\
\text { school }\end{array}$ & Housewife & Widow & $\begin{array}{l}\text { Freelance } \\
\text { (dead) }\end{array}$ & 4 & 15 \\
\hline 4 & Volunteer & 46 & $\begin{array}{l}\text { Primary } \\
\text { school }\end{array}$ & Housewife & Married & Freelance & 4 & 12 \\
\hline 5 & Volunteer & 54 & $\begin{array}{l}\text { Primary } \\
\text { school }\end{array}$ & Housewife & Single & - & - & 15 \\
\hline 6 & Volunteer & 60 & $\begin{array}{l}\text { College } \\
\text { degree }\end{array}$ & Retired & Married & Accountant & 3 & 8 \\
\hline 7 & Volunteer & 42 & $\begin{array}{l}\text { Middle } \\
\text { school }\end{array}$ & Housewife & Married & Freelance & 4 & 14 \\
\hline 8 & Volunteer & 46 & Diploma & Housewife & Married & Teacher & 2 & 15 \\
\hline 9 & Volunteer & 45 & $\begin{array}{l}\text { Bachelor's } \\
\text { degree }\end{array}$ & Housewife & Single & - & - & 9 \\
\hline 10 & Volunteer & 46 & $\begin{array}{l}\text { Primary } \\
\text { school }\end{array}$ & Housewife & Married & Freelance & 4 & 14 \\
\hline 11 & Volunteer & 58 & Diploma & Housewife & Married & Retired & 4 & 15 \\
\hline 12 & Volunteer & 48 & $\begin{array}{l}\text { Middle } \\
\text { school }\end{array}$ & Housewife & Married & Freelance & 3 & 15 \\
\hline 13 & Volunteer & 53 & $\begin{array}{l}\text { Primary } \\
\text { school }\end{array}$ & Housewife & Married & Freelance & 2 & 12 \\
\hline 14 & Volunteer & 47 & $\begin{array}{l}\text { High } \\
\text { school }\end{array}$ & Housewife & Married & Paramedic & 3 & 3 \\
\hline 15 & Volunteer & 40 & $\begin{array}{l}\text { Middle } \\
\text { school }\end{array}$ & Housewife & Single & - & - & 5 \\
\hline 16 & Volunteer & 38 & $\begin{array}{l}\text { Middle } \\
\text { school }\end{array}$ & Housewife & Married & Freelance & 2 & 8 \\
\hline 17 & Volunteer & 40 & $\begin{array}{l}\text { Middle } \\
\text { school }\end{array}$ & $\begin{array}{l}\text { Carper } \\
\text { weaver }\end{array}$ & Single & - & - & 7 \\
\hline 18 & Volunteer & 57 & $\begin{array}{l}\text { College } \\
\text { degree }\end{array}$ & Retired & Married & No job & 5 & 12 \\
\hline 19 & Volunteer & 52 & Diploma & Housewife & Married & Freelance & 2 & 15 \\
\hline 20 & Volunteer & 51 & $\begin{array}{l}\text { High } \\
\text { school }\end{array}$ & Housewife & Married & Freelance & 4 & 15 \\
\hline 21 & Volunteer & 70 & Primary & $\begin{array}{l}\text { Housewife } \\
\text { Page 6/14 }\end{array}$ & Widow & Freelance & 3 & 15 \\
\hline
\end{tabular}




\begin{tabular}{lllllllll} 
& \multicolumn{2}{c}{ school } & & (dead) & & \\
\hline 22 & Volunteer & 49 & $\begin{array}{l}\text { Middle } \\
\text { school }\end{array}$ & Housewife & Married & Freelance & 5 & 10 \\
\hline 23 & Volunteer & 50 & $\begin{array}{l}\text { Middle } \\
\text { school }\end{array}$ & Housewife & Married & Retired & 4 & 4 \\
\hline 24 & Volunteer & 70 & Illiterate & Housewife & Widow & $\begin{array}{l}\text { Freelance } \\
\text { (dead) }\end{array}$ & 4 & 10 \\
\hline 25 & Volunteer & 38 & Diploma & Housewife & Married & Employee & 1 & 12 \\
\hline 26 & $\begin{array}{l}\text { Current } \\
\text { instructor }\end{array}$ & 53 & $\begin{array}{l}\text { Bachelor's } \\
\text { degree }\end{array}$ & $\begin{array}{l}\text { Healthcare } \\
\text { worker }\end{array}$ & Married & Engineer & 2 & 20 \\
\hline 27 & $\begin{array}{l}\text { Previous } \\
\text { instructor }\end{array}$ & 50 & $\begin{array}{l}\text { Bachelor's } \\
\text { degree }\end{array}$ & Expert & Married & Engineer & 2 & 18 \\
\hline & & & & & & \\
\hline
\end{tabular}

\section{Results of the first cycle}

Stage 1: Qualitative data analysis yielded 1000 codes irrespective of repeated codes. After categorizing the codes, four subcategories emerged: role confusion, inadequate volunteer training, deficits in attracting and keeping volunteers, and being unfamiliar to the public. One main theme was also extracted named "unfertilized capacity". For the quantitative section, questionnaires were completed by the volunteers including questions about different aspects of their performance and problems they faced at the beginning of the study. In the first cycle of the study, $80 \%$ of the volunteers thought that their main responsibility was to educate the families under coverage. Moreover, their main problems were as follows: not having a clear plan (100\%), disorganization in holding educational plans related to the volunteers $(80 \%)$, lack of practical skill training alongside theoretic instruction (56\%), not benefiting from the volunteers' abilities $(52 \%)$, and not having a place for holding the educational sessions (52\%). From the volunteers' perspective most of the problems stemmed from lack of support from authorities (88\%) and little interaction between the volunteer and instructor (76\%). Public survey was another method for data collection on the healthcare volunteers' performance. For this reason, 300 forms were completed by people who referred to the center. The results showed that $288(96 \%)$ of the respondents did not know that health volunteers even existed in the system and did not receive any services through them. From the results obtained from the first cycle, we can conclude that the volunteers did not have any plans for teaching the public, were not familiar with some of their roles, and thought that their only role was to teach people, their teaching material was only the pamphlets the center had given them, they received no suitable feedback by authorities, there were some weaknesses in their management, and they did not have suitable solutions for their occupational problems. One of the main duties of the healthcare system is to provide healthcare services actively and effectively. To attain this goal, the culture of public participation should be established and improved in the society. Volunteer empowerment based on their needs as well as the public's needs is done in a participatory manner.

Stage 2: After identifying the existing condition, the results of the first stage were shared with the participant. Based on the determined problems and prioritizing them, the plan for enhancing their capabilities was designed with their own cooperation. 
Stage 3: In this stage, the action plan for each problem was determined by the volunteers based on the problems and strategies. The action plan was designed based on the nine problems identified in the first cycle (lack of planning for volunteers, unsuitable time management for holding educational classes, undefined volunteer responsibility, need for teaching practical skills, lack of educational facilities, not having a suitable place to hold classes, lack of ability to interact with people, deficits in documenting volunteer performance, and lack of motivating and encouraging factors for better volunteer participation.

Stage 4: At the end of the first cycle, the progress in action plans and volunteer empowerment was determined through reflection, observing volunteer performance, interviews with volunteers, and recompletion of the survey forms by people referring to the center (Ghamar BaniHashem Comprehensive Healthcare Center). We found that the volunteers were eager to learn and perform their duties. Recompletion of the public survey forms showed that their unfamiliarity with healthcare volunteers reduced from $96 \%$ to $88 \%$ and the volunteers put more effort into their work in this stage. Moreover, in the two interviews done, the volunteers emphasized on the need for the instructor's support repetition of some educational content (such as vital sign measurement skills), and using participatory methods in education.

\section{Results of the second cycle}

This cycle began with reflecting on the first stage and then after planning for change, immersion in action and evaluation were done.

Reflection: The second cycle of the action research began with the volunteers' reflection. They expressed their experiences about the new knowledge and skill they had gained, the changes in their emotions and performance, their effects on their daily lives, and the lessons they had learned.

Action plan: After the reflection sessions, the participants identified the problems and challenges they faced and designed a new plan. A list of problems was prepared concerning issues such as lack of using participatory methods in education, deficits in health volunteer records and completing their performance forms by the instructor, need for repeating practical training, lack of awareness about how to refer people to use healthcare facilities, weaknesses in the teaching role of volunteers, unfamiliarity of the public with healthcare volunteers, and lack of educational facilities. Based on the mentioned problems, the volunteers designed the action plan for the second cycle of the action research.

Immersion in action: Researcher's reflection is the facilitator of one of the important parts of immersion in action. This reflection was done in the following domains: reflection on the research content, process, and issues.

Evaluation: At the end of the second cycle, evaluation was done. For this reason, quantitative methods such as public surveys, assessing volunteer records, volunteer performance monitoring checklist and Kirkpatrick model for assessing the effectiveness of the educational program were used. We also used qualitative methods such as interview, self-report, and focused group discussion for evaluation. In this stage, the volunteers checked the publics views and opinions. 300 forms were handed to the people referring to the center. We found that 60 (20\%) people were familiar with healthcare volunteers and their programs, $48(16 \%)$ had moderate familiarity, and $192(64 \%)$ did not know about such programs. The public's familiarity with health volunteers had 
increased from $4 \%$ to $36 \%$. The educational program for health volunteers was assessed according to Kirkpatrick's four evaluation domains of volunteer satisfaction with different aspects of the program, amount of acquired knowledge, amount of acquired skill, and effectiveness of the program. The results showed that most participants $(n=19,76 \%)$ were satisfied with different aspects of the program. At the second and third level of Kirkpatrick's model, the volunteers' acquired knowledge and skill was compare using paired t test, indicating a significant increase in these domains $(P=0.0001)$. Finally, in the final level of the mentioned model, the effect of the educational program on the volunteers' work environment was assessed according to their own view point. The scores ranged from 21 to 28 with a mean $\pm S D$ of $23.8 \pm 1.92$. We found that all volunteers perceived this course as effective.

Four focused group sessions were held for the volunteers in which they shared the results of the first and second cycles and compared them. The following points were mentioned in these sessions:

- The classes differed from before. We did not understand all the content before, but now we do.

- It is a good experience to work together.

-We must gain more information and skills.

- The program was desirable and satisfactory.

- There are still some problems in transferring health messages to people.

A 60-year-old volunteer with eight years of volunteer work stated: "This program has excellent skills and everyone, even older volunteers with less literacy level are encouraged to participate. We did many things before, but it is more organized now'.

At the end of the second cycle of the research, six interviews were done with the volunteers. Content analysis was done again on the collected data. In the triangulation of the results obtained from the interviews, focused groups, and daily notes of the volunteers as well as the documents, 300 initial codes were obtained. After categorization, 24 sub-subcategories, four subcategory, and two main themes for the effects of the empowerment program on the volunteers (table 2). Moreover, table 3 shows the results at the beginning of the first cycle and the end of the action research.

Table 2: The categories and subcategories of the program's effects on empowering health volunteers 
Effective instruction

Skill improvement

Facilitating communication and group work

Support and mentorship

$$
\text { Controlled group performance }
$$

Table 3: Comparing the changes at the beginning of the fist cycle and the end of the action research 


\section{Problems and Actions \\ Before the first cycle \\ End of the first cycle \\ End of the second cycle}

Class order
Class cancellation without notice for two times
Disorganized

classes and

constant

cancellation

without notice
Orderly and organized class

schedule, in case the instructor could not come (with prior notice) a substitute (an expert or another volunteer) would be introduced

\section{Orderly presence of the volunteers in the classes

\begin{abstract}
Disorganization, absence or on time presence, absence without prior notice
\end{abstract}

Interference in information communication and content transfer

Lack of order and access to information, being limited to contents of educational books

Location of the
class

Home of volunteers

$\begin{array}{ll}\text { Content } & \text { Only by the } \\ \text { presentation in } & \text { instructor }\end{array}$
the class

Regular public Very limited training program
Less disorganization, most absence were without prior notice
Limited absence with prior notice
Creating groups in social media regarding the volunteers' activities, using the group and educational pamphlets for transferring scientific content
Most volunteers had joined the group, they borrowed educational books and copied them, use of other valid sources

A room in the healthcare center

A room in the healthcare center

Participation of both the instructor and the volunteer
Participation of both the instructor and the volunteer as well as other invited experts
Monthly sessions at the local center for religious activities, training at religious gatherings, recreational activities with family and friends
Qualitative and quantitative increase in public education, volunteers now have plans for public education themselves
Every three months but still mostly by the instructor
Every three months with the guidance of the instructor volunteer

record keeping
Annually and only by the instructor

Only for
participating in
the classes

Limited and dispersed
Increased sense of responsibility for cooperating with the instructor and collecting family statistics

Dome with more group participation and follow-up
Increased sense of responsibility for cooperating with the instructor and collecting family statistics

Individual and group follow-up authorities

\section{Discussion}

The results of analyzing qualitative and quantitative data showed that the two-cycle program for enhancing and empowering healthcare volunteers was able to increase the volunteers' competence and ability and lead to 
higher independence. One of the needs the volunteers mentioned in this study was better explanation of their roles and responsibilities and a coherent familiarity program. In other parts of the world, the main challenges of health volunteers were that they were not fully familiar with their roles and were not supported for the services they provide (144). Lack of practical skill training was a setback for empowering themselves. Moreover, in qualitative analysis, they mentioned that their educational programs were inadequate. In one study, the volunteers stated that there were several obstacles in providing volunteer care services for patients with syphilis, among which was lack of knowledge about services that should be provided (22). Healthcare volunteers demanded that program planners pay more attention to teaching the required skills so that they could perform their roles better (25).

Through qualitative analysis, we found that action without basic and fundamental training as well as lack of educational facilities were the main problems volunteers faced. Providing necessary educational facilities increases motivation and reduces the rate of quitting (140). The healthcare system should plan for providing suitable training and improve their service providing standards (104). Inadequate support and supervision along with weak communication skills in volunteers and instructors were among other problems that the volunteers mentioned. In an ethnographic study in Uganda, the researchers found that the volunteers needed authorities to clarify how they should communicate with the healthcare team, local government, and medical structures (149). Moreover, volunteers in south Africa stated that unsuitable communication with each other and inadequate team supervision were their weak points (150). Lack of feedback on their activities was another issue the volunteers mentioned in our study. In another study in rural areas of Zambia, although volunteers had a positive view about their duties, their program had several weaknesses with respect to suitable supervision, positive feedback from the system, and facilities, which indicated that their program needed to be improved (151).

We found that the public was not familiar with the healthcare volunteers. This leads to inadequate service providing since they are an important communication bridge between the health system and people requiring healthcare services. Better familiarity with healthcare volunteers increases people's satisfaction and cooperation. For example, in China, most elderly welcomed volunteer care after being introduced to them and their programs (104). The results of the first cycle (in the identification stage) showed that volunteers have unfertilized capacities, and considering this potential, change was necessary. This finding is consistent with many other studies $(155,159-161)$.

The results of the second cycle of the action research showed that our study had enhanced the volunteers' capabilities. The changes that had occurred at the end of the study were mostly related to their educational needs and access to required educational content. They found their instruction to be effective and their educational needs were met. Other researchers also found that education improved volunteer service providing in the healthcare system (25). However, several studies in Iran and other countries showed that educational programs were not effective for health volunteers $(22,96,97,144)$. This contradictory finding could be attributed to factors such as not paying attention to the volunteers' educational needs and lack of suitable educational methods. The volunteers' biggest challenge in our study was inadequacy of instruction. At the end of the study, we found that their knowledge had increased and they performed their duties much better than before. Volunteer satisfaction is an advantage in such programs. In our study the volunteers were actively involved in needs assessment, which is the nature of action research. The results of a systematic review and 
meta-analysis on learning and participatory action in female volunteers for enhancing neonatal and maternal health in India, Bangladesh, Malave, and Nepal showed that their duties (which were based on participatory action and providing educational needs), reduced the rate of mortality in these regions (142).

Ultimately, we found that the volunteers' capabilities had increased considerably leading to higher rates of effectiveness. Data analysis at the end of the study yielded the main theme of enhanced competence. This is while the theme "unfertilized capacity" at the beginning of the study indicated lack of competence and capability. This is in line with several other studies showing that volunteers have a high potential in promoting health-related and social welfare $(157,161,180,182)$.

\section{Limitations And Future Research}

This study was done in a comprehensive healthcare center in Shiraz, the capital of Fars province. Qualitative study, especially action research, cannot be generalized for other settings and we suggest similar studies be done in smaller cities and towns. Future studies using the action research method on volunteers and other stakeholders would help identify existing challenges in the system.

\section{Conclusion}

Clarification of the volunteers' roles and supporting volunteers to improve their knowledge and skills with coherent planning based on their educational needs, are appropriate management plans to attract and retain volunteers. By presenting their services to the society, they will be empowered and motivated to continue.

\section{Declarations}

\section{Ethics approval}

This study was approved by the Ethics Committee of Shiraz University of Medical Sciences, Shiraz, Iran (No: IR.sums.REC.1394.112). All participants were fully informed about the study objectives and provided written informed consent for their participation.

\section{Consent for publication}

Not applicable

\section{Availability of data and materials}

It is provided by request of the first author

\section{Competing interests}

All authors declared no potential conflicts of interest with respect to the research, authorship, and/or publication of this article. 


\section{Funding}

This article was extracted from a PhD dissertation in nursing education, which was financially supported by the Research Vice-chancellor of Shiraz University of Medical Sciences (grant No. 94-7577). The funder had no role in the design of the study, nor in the collection, analysis, and interpretation of the data and in writing the manuscript.

\section{Authors' contributions}

F V, M M, S Y: Conceptualization, Methodology, Software, Data curation, Writing- Original draft preparation, Visualization, Investigation, Supervision, Validation, Writing- Reviewing and Editing. M. T I: Conceptualization, Methodology, Investigation, and Supervision. and all authors contributed to revisions. All authors have approved the submitted version and agree to be personally accountable for the author's own contributions.

\section{Acknowledgements}

The present article was extracted from the thesis written by the first author in partial fulfillment of the requirements for PhD in nursing education (Grant NO: 75577). Authors would like to express their gratitude to the healthcare volunteers for participating in this study. 